Pharmaceutical and Biomedical Research

\title{
Kojic acid-derived tyrosinase inhibitors: synthesis and bioactivity
}

\author{
Seyedeh Mahdieh Hashemi, Saeed Emami* \\ Department of Medicinal Chemistry, Pharmaceutical Sciences Research Center, Faculty of Pharmacy, Mazandaran University \\ of Medical Sciences, Sari, Iran
}

Received: Dec 14, 2014, Revised: Jan 11, 2015, Accepted: Jan 18, 2015

\begin{abstract}
Tyrosinase is a key enzyme for melanin biosynthesis, catalyzing the oxidation of L-tyrosine to L-dopaquinone. The tyrosinase inhibition is an effective approach to control hyperpigmentation in human skin and enzymatic browning in fruits and vegetables. Kojic acid is a naturally-occurring tyrosinase inhibitor which has been clinically used to treat the hyperpigmentation of skin. However, kojic acid as a hydrophilic small-molecule has insufficient inhibitory activity and stability, with considerable toxicity. To overcome these drawbacks, synthetic derivatives of kojic acid were developed, which exhibited enhanced tyrosinase inhibitory activity and more favorable stability relative to kojic acid. In this context, the synthesis and biological activity of kojic acid derivatives as tyrosinase inhibitors have been highlighted.
\end{abstract}

Keywords: Kojic acid, 4H-pyran-4-one derivatives, enzyme inhibitors, structural modifications

Pharm Biomed Res 2015; 1(1): 1-17～DOI: 10.18869/acadpub.pbr.1.1.1

\section{Introduction}

Melanin is a dark pigment produced by about $10 \%$ of skin cells in the innermost layer of the epidermis (1). This compound is a heteropolymer of indole derivatives and is produced inside melanosomes through a series of oxidative reactions involving the amino acid tyrosine in the presence of the enzyme tyrosinase (Fig. 1). The type and amount of produced melanin in the melanosomes generates the actual color of the skin (2). Melanogenesis is a physiological process, which plays an important role in the prevention of sun-induced skin injury. Although the melanin production in human skin is a major defense mechanism against ultraviolet (UV) light, the accumulation of an excess of epidermal pigments can causes various hyperpigmentation disorders, such as melasma, age spots, and sites of actinic damage (3).

Tyrosinase (EC 1.14.18.1), also known as polyphenoloxidase (PPO), is a coppercontaining bifunctional enzyme with a molecular weight of approximately 60-70 $\mathrm{kDa}$ in mammals and is found exclusively in melanocytes $(1,4)$. It catalyzes two distinct reactions of melanin synthesis (Fig. 1); the hydroxylation of

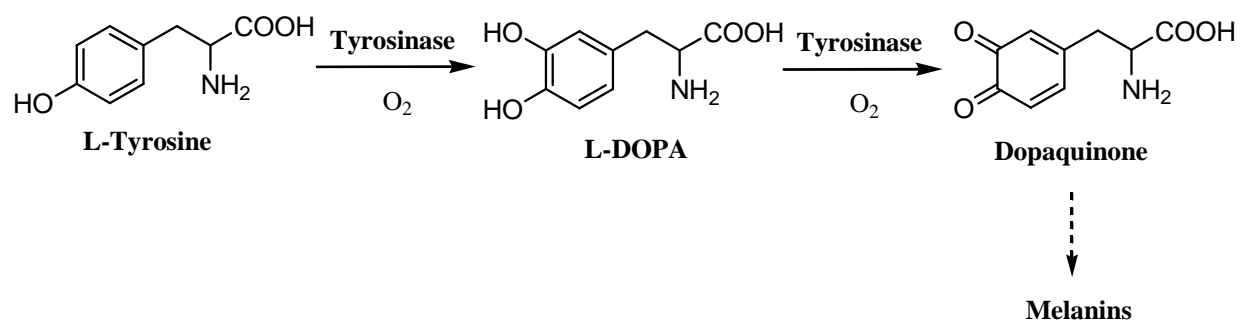

Figure 1 The role of tyrosinase enzyme in the melanogenesis process 
L-tyrosine to form 3,4dihydroxyphenylalanine (L-DOPA) by monophenolase action and the oxidation of L-DOPA to the corresponding $o$ dopaquinone by diphenolase activity (5). Dopaquinone is highly reactive and can polymerize spontaneously to form melanin in a series of reaction pathways (6). The tyrosinase can be considered as a ratelimiting enzyme in the melanin biosynthesis (7). Accordingly, tyrosinase inhibitors significantly reduce pigmentation in melanosomes and avoid excessive melanogenesis. Some tyrosinase inhibitors have useful application in cosmetics and pharmaceutical products for the prevention of the overproduction of melanin in the epidermis (8). On the other hand, melanogenesis affects the color quality and flavor of foods. The enzymatic action of tyrosinase causes the browning in fruits and vegetables. Thus, tyrosinase enzyme plays an important role in loss of nutritional and market values of foods. In the food industry, tyrosinase inhibitors, especially from natural sources have great potential in controlling the quality and economics of fruits and vegetables (9). Many efforts have been spent in the search for effective and safe tyrosinase inhibitors, and a large number of naturally occurring and synthetic tyrosinase inhibitors were extensively reported (10-12). However, only few of them are practically applicable due to their weak intrinsic activities or safety concerns. Therefore, it is still necessary to search and develop novel tyrosinase inhibitors with potent activity and lower side effect (4).

Kojic acid

Kojicacid (5-hydroxy-2-(hydroxymethyl)-4Hpyran-4-one, 1) (Fig. 2) is one of the metabolites<smiles>O=c1cc(CO)occ1O</smiles>

(1)

Figure 2 The structure of kojic acid produced by various fungal or bacterial strains such as aspergillus and penicillium and has been used in many countries as a skin-whitening agent because of its tyrosinase inhibitory activity on melanin synthesis. The biological activities of kojic acid are attributed to its $\gamma$-pyranone structure that contains an enolic hydroxyl group. If the enolic hydroxyl group is protected, its tyrosinase inhibitory activity is completely lost. It acts by chelating copper at the active site of the tyrosinase enzyme (13). Melanocytes that are treated with kojic acid become nondendritic and have decreased melanin content (14). Kojic acid was reported to have a highsensitizing potential and to potentially cause irritant contact dermatitis. However, it is useful in patients who cannot tolerate hydroquinone and it may be combined with a topical corticosteroid to reduce irritation (15). Additionally, it also acts as an antioxidant and scavenges reactive oxygen species that are released excessively from cells or generated in tissue or blood (16). The reaction of kojic acid with metal salts of aluminium, chromium, cobalt, copper, gold, indium, iron, nickel, manganese, palladium, vanadium, and zinc results in the formation of stable metal kojate complexes (17-20). Due to its iron chelating activity, kojic acid and its derivatives play an important role in the management of iron-overload diseases such as $\beta$-thalassemia or anemia (21-25). Moreover, various biological effects including antibacterial $(26,27)$, antifungal $(28,29)$, antiviral (30), anti-inflammatory (31), antineoplastic (32-34), pesticide (35), radioprotective (20), antidiabetic (36), and anticovulsant $(37,38)$ activities have been reported for kojic acid and its derivatives.

Kojic acid derivatives as tyrosinase inhibitors

Kojic acid is a naturally-occurring tyrosinase inhibitor, which has been clinically used to treat the hyperpigmentation of skin. However, kojic acid has insufficient inhibitory activity and stability, with considerable toxicity. To overcome these drawbacks, synthetic derivatives of kojic acid were developed. We discuss here the major modifications 
which were made on the kojic acid structure.

Conversion of $\gamma$-pyranone to 4-pyridinone: O-1 modification

The replacement of oxygen in the $\gamma$ pyranone ring with nitrogen resulted in 4pyridinone analogs of kojic acid (Fig. 3).<smiles></smiles>

Kojic acid

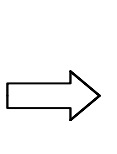

(1)<smiles></smiles>

4-Pyridinone analogs
Figure 3 O-1 modification in kojic acid
Accordingly,

hydroxypyridinone-L-phenylalanine

conjugates 5 (Fig. 4), starting from kojic acid was synthesized by $\mathrm{Li}$ et. al. and evaluated against mushroom tyrosinase (39). It was found that compound containing 1-octyl moiety $\left(\mathrm{R}=n-\mathrm{C}_{8} \mathrm{H}_{17}\right)$ had potent inhibitory effect against mushroom tyrosinase. MTT assay indicated that this compound was non-toxic to tested cell lines. For the synthesis of compounds, firstly kojic acid (1) was $O$-benzylated by benzyl chloride, and then reacted with an appropriate alkylamine to give compound 3. The alcoholic compound $\mathbf{3}$ was conjugated with $N$-protected Lphenylalanine by using EDC and DMAP.

$$
\text { a series }
$$

Finally, $N$-deprotection was carried out by hydrogenation at $30 \mathrm{psi} \mathrm{H}_{2}$ for 5-6 h at room temperature to give target compounds 5 (39).

Saghaie et al. synthesized a series of 3-hydroxy4-pyridinones 9 starting from kojic acid in high yield (Fig. 5), and evaluated them for their inhibitory activity toward tyrosinase enzyme using dopachrome method (40). As illustrated in Fig. 5, the amine insertion in the $O$-benzyl kojic acid (2) resulted in compound $\mathbf{6}$, which subsequently oxidized to aldehyde 7 . Condensation of aldehyde $\mathbf{7}$ with aniline derivatives gave Schiff base 8. Reduction of $\mathrm{C}=\mathrm{N}$ bond and $O$-debenzylation in compound $\mathbf{8}$ by using $\mathrm{Pd} / \mathrm{C}$ hydrogenation afforded final compounds 9 . Their biological results show that all synthesized compounds have inhibitory effect on tyrosinase activity. Among compounds studied those containing two free hydroxyl group were more potent than their analogues with one hydroxyl group. Also, substitution of a methyl group on position $\mathrm{N}_{1}$ of the hydroxypyridinone ring seems to confer more inhibitory potency (40).

\section{Esterification of 2-(hydroxymethyl) group of} kojic acid

The primary alcoholic group of kojic acid can be esterified with different acids. However, the convenient method for preparation of kojic esters is via chloro-kojic acid (10) and subsequent nucleophilic substitution with a suitable carboxylate salt (Fig. 6).

Nitric oxide (NO) is an important inflammatory mediator, synthesized by inducible nitric oxide synthase (iNOS).<smiles>COC(OC)C(=O)O</smiles>

(1)<smiles>O=c1cc(CO)occ1OCc1ccccc1</smiles>

(2)
$\mathrm{Bn}=$ Benzyl group<smiles>CCn1cc(OCc2ccccc2)c(=O)cc1CO</smiles>

(3)<smiles>NC(Cc1ccccc1)C(=O)OCc1cc(=O)c(O)cn1P</smiles>

(5)

$\mathrm{R}=\mathrm{CH}_{3} ; \mathrm{C}_{2} \mathrm{H}_{5} ; n-\mathrm{C}_{4} \mathrm{H}_{9}$; $n-\mathrm{C}_{6} \mathrm{H}_{13} ; n-\mathrm{C}_{8} \mathrm{H}_{17} ; n-\mathrm{C}_{10} \mathrm{H}_{21}$

Figure 4 Synthesis of hydroxypyridinone-L-phenylalanine conjugates 5 
<smiles></smiles>

(1)

(2)

(6)

$\mathrm{Bn}=$ Benzyl group

$\mathrm{R}=\mathrm{H}, \mathrm{CH}_{3}$<smiles>[R]c1ccc(Br)c(CC)c1</smiles>

(7)<smiles>[R]c1ccccc1/N=C/c1cc(=O)c(OCCCC)cn1[R]</smiles>

$\mathrm{R}=\mathrm{H}, \mathrm{CH}_{3}$

Figure 5 Synthesis of 3-hydroxy-4-pyridinones 9<smiles>O=c1cc(CO)occ1O</smiles>

(1)<smiles>[R]C(=O)OCC(C)=O</smiles>

(10)<smiles>[R]C(=O)OCc1cc(=O)c(O)co1</smiles>

(11)

Figure 6 The convenient method for preparation of kojic esters 11

Overproduction of NO can lead to inflammatory diseases (41). Thus, much effort has been focused on finding potent inhibitors of NO production. However, there have been few studies on the use of kojic acid and its derivatives as NO inhibitors. Recently, a series of kojic acid derivatives $\mathbf{1 2}$ containing ester linkage, and kojicbenzoates 16 containing adamantane moiety were synthesized and evaluated their inhibitory activities against tyrosinase and NO production. As depicted in Fig. 6, the reaction of kojic acid with thionyl chloride produces compound $\mathbf{1 0}$, which is conveniently $O$-methylated to give compound 13 using dimethylsulfate and potassium carbonate in acetone under reflux conditions. Chlorides $\mathbf{1 0}$ and $\mathbf{1 3}$ react with potassium salts of benzoic acids or of cinnamic acids in DMF at $110-120{ }^{\circ} \mathrm{C}$ to give the corresponding ester derivatives 12 (Fig. 7). Adamantylbenzoic acids 15 were synthesized by reacting benzoic acids with 1-adamantanol in trifluoroacetic acid (TFA) under reflux conditions. Adamantylbenzoic acids $\mathbf{1 5}$ reacted with potassium hydroxide in methanol to afford the potassium salts. After methanol removal, the potassium salts react with 
corresponding ester derivatives 16 (Fig. 8)

(42). The obtained biological results revealed that 3,4-methylenedioxy cinnamic acid ester of kojic acid (12c) exhibited more potent inhibitory effect on tyrosinase than kojic acid. The structure of compound12c (Fig. 9) comprises two main parts: a chelating part of kojic acid and a hydrophobic part of cinnamic acid. However, the hydroxybenzoate derivatives of kojic acid containing the adamantyl moiety showed no inhibitory activity. The reason for no inhibition may be either steric hindrance of the adamantyl moiety or insufficient copper chelating tendency

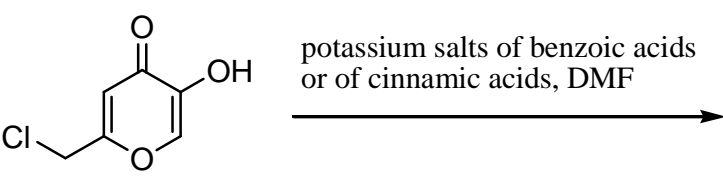

(10)

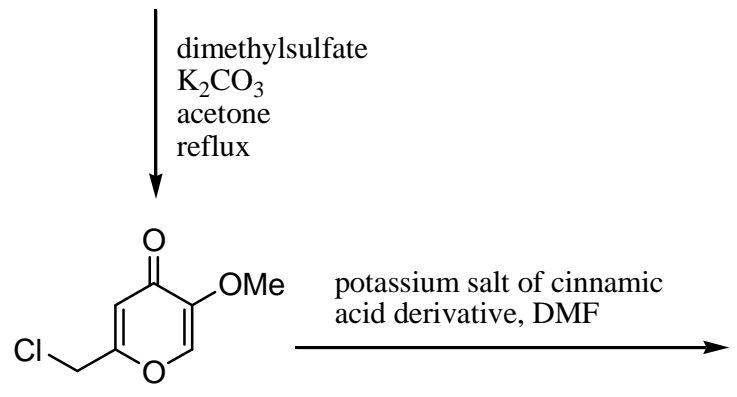

(13)<smiles>[Y]Oc1ccc(C(=O)OCc2cc(=O)c(O)co2)cc1O</smiles>

12a, $\mathrm{Y}=\mathrm{CH}_{2}$ 12b, $\mathrm{Y}=\mathrm{CH}_{2} \mathrm{CH}_{2}$<smiles>O=C(/C=C/c1ccc2c(c1)O[Y]O2)OCc1cc(=O)c(O)co1</smiles>

12c, $\mathrm{Y}=\mathrm{CH}_{2}$

12d, $\mathrm{Y}=\mathrm{CH}_{2} \mathrm{CH}_{2}$<smiles>COc1coc(COC(=O)/C=C/c2ccc3c(c2)OCO3)cc1=O</smiles>

$12 \mathrm{e}$

Figure 7 Synthesis of kojic esters 12a-e<smiles>[R]OC(=O)c1cc(C23CC4CC(CC(C4)C2)C3)c(PCCCCC)cc1[R6]</smiles>

(15)<smiles>[R6]c1cc([R8])c(C23CC4CC(CC(C4)C2)C3)cc1C(=O)OCc1cc(=O)c(O)co1</smiles>

16a, $\mathrm{R}_{1}=\mathrm{OMe}, \mathrm{R}_{2}=\mathrm{OH}$ 16b, $\mathrm{R}_{1}, \mathrm{R}_{2}=\mathrm{OH}$

Figure 8 Synthesis of kojic-benzoate esters 16 containing adamantyl moiety 


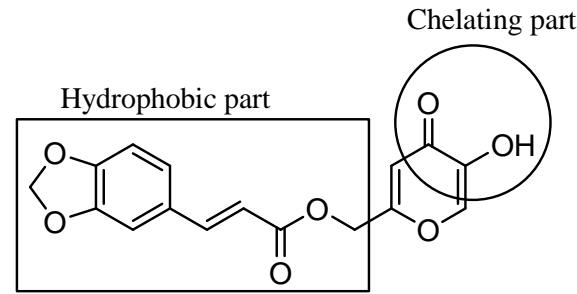

(12c)

Figure 9 Structure of 3,4-methylenedioxycinnamic acid ester of kojic acid (12c)

between kojic acid and the 2-hydroxy benzoic acid moiety.

In another study, benzoate ester derivatives of kojic acid, with and without adamantyl moiety were synthesized (Fig. 10).
Benzoate derivatives $\mathbf{1 7}$ that did not contain an adamantyl moiety showed potent tyrosinase inhibitory activities. In contrast, compounds $\mathbf{1 8}$ showed potent depigmenting activity without tyrosinase inhibitory activity. This is the first study showing the depigmenting activity of kojic acid derivatives without tyrosinase inhibitory activity (43). Cho and co-workers have synthesized cinnamate derivatives of kojic acid by various esterification methods, for use as depigmenting agents. In this report, to obtain the cinnamate ester of kojic acid (compound 12c), the nucleophilic addition of the potassium salt of cinnamic acid to kojyl chloride was carried out (Fig. 11). Interestingly, the side product (20) showed<smiles>[R]c1ccc(C(=O)OCc2cc(=O)c(O)co2)cc1</smiles>

(17)<smiles>O=C(OCc1cc(=O)c(O)co1)c1cc[R]c(C23CC4CC(CC(C4)C2)C3)c1</smiles>

(18)

$\mathrm{R}=4-\mathrm{OMe} ; 4-\mathrm{OH} ; 2,4-(\mathrm{OH})_{2} ; 2-\mathrm{OH}, 4-\mathrm{OMe} ; 2,4-(\mathrm{OMe})_{2}$

Figure 10 Structure of benzoic acid esters of kojic acid (17 and $\mathbf{1 8})$<smiles>COC(=O)/C=C/c1ccc2c(c1)OC[C@H]2OC(=O)/C=C/c1ccc2c(c1)OCO2</smiles>

Byproduct (20)

Figure 11 Preparation of cinnamate derivatives of kojic acid (compounds 12c and 20) 
more potent depigmenting activity $\left(\mathrm{IC}_{50}=23.51 \mu \mathrm{M}\right)$ than compound 12c $\left(\mathrm{IC}_{50}>\right.$ $100 \mu \mathrm{M})$ which is the parent compound of the side product. However, it has no tyrosinase inhibitory activity (44).

A novel kojic acid derivative containing trolox (21), namely ( \pm )-5-hydroxy-4-oxo-4H-pyran-2yl-methyl 6-hydroxy-2,5,7,8tetramethylchroman-2-carboxylate (22a, Fig. 12), was synthesized (45). Indeed, the two biologically active compounds, kojic acid and trolox, were conjugated via an ester bond as they are expected to have dual action. The antioxidant activity and the tyrosinase inhibitory activity of kojic acid derivative 22a on melanogenesis were evaluated. Compound 22a exhibited potent tyrosinase inhibitory activity and radical scavenging activity. Limited structureactivity relationship (SAR) investigations indicated that the tyrosinase inhibitory activity may originate from the kojic acid moiety, and the radical scavenging activity may be due to the phenolic hydroxyl group of trolox. Compound 22a also exhibited potent depigmenting activity in a cell-based assay. The limited SAR investigations revealed that the depigmenting activity of 22a may be due to the synergistic activities of kojic acid and its trolox moiety (45). As presented in Fig. 13, kojyl chloride derivatives 10 or 13 reacted with potassium salts of trolox, 4-hydroxybenzoic acid or 6hydroxynaphthoic acid in DMF at 110-120 ${ }^{\circ} \mathrm{C}$ to give the corresponding ester derivatives $\mathbf{2 2 a}-\mathbf{d}$ (45).<smiles>Cc1c(C)c2c(c(C)c1O)CCC(C)(C(=O)O)O2</smiles>

(21), Trolox<smiles>Cc1c(C)c2c(c(C)c1O)CCC(C)(C(=O)OCc1cc(=O)c(O)co1)O2</smiles>

(22a)

Figure 12 Structures of antioxidant compound trolox (21) and kojic acid-trolox conjugate (22a)

(10)

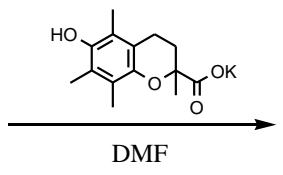

(10)<smiles>COc1ccc(O)cc1CCCCC(=O)c1ccc2cc(O)ccc2c1</smiles>

(10)<smiles>O=C(OCc1cc(=O)c(O)co1)c1ccc(O)cc1</smiles>

(13)

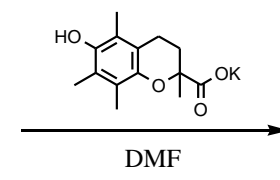

(22c)<smiles>Cc1c(C)c2c(c(C)c1O)CCC(C(=O)OCc1cc(=O)c(O)co1)O2</smiles>

(22a)<smiles>COc1coc(COC(=O)C2(C)CCc3c(C)c(O)c(C)c(C)c3O2)cc1=O</smiles>

(22d)

Figure 13 Synthesis of kojic acid-trolox conjugate and related compounds 
Kojic acid derivatives conjugated with amino acids

In a report by Noh et al. (46), kojic acid has been coupled with amino acids to obtain kojic acid-amino acid amide conjugates $\mathbf{2 4}$ as new stable tyrosinase inhibitors (Fig. 14). Firstly, the primary alcohol of kojic acid was reacted with 1,1'-carbonyldiimidazole (CDI) and then coupled to the resin-bounded amino acids. In this reaction, the kojyl moiety is connected to the amino acid via a carbamate linker. After cleavage of the kojic acid-amino acid amide (24, KA-AA- $\mathrm{NH}_{2}$ ) from the resin, it was characterized by MALDI-TOF mass spectroscopy. The conjugates of different amino acid amides with kojic acid were evaluated for their inhibitory activity on mushroom tyrosinase. The results showed that most of conjugates had better inhibitory activity than the parent molecule kojic acid. When amino acids such as phenylalanine, tryptophan, tyrosine, and histidine, which possess aromatic side chains, were conjugated to kojic acid, the tyrosinase inhibitory activity was enhanced dramatically. Noh et al. suggested that the aromatic residue of mentioned amino acids may contribute to the binding of the inhibitor to the hydrophobic pocket of the enzyme. Further studies showed that kojic acid-phenylalanine amide conjugate (24a, KA-F-NH $\mathrm{NH}_{2}$, Fig. 15) showed the strongest inhibitory activity, which was maintained for over 3 months at $50{ }^{\circ} \mathrm{C}$, and acted as a noncompetitive inhibitor (46).

Kim group synthesized a series of kojic acidtripeptides by solid-phase parallel synthesis and evaluated them as tyrosinase inhibitors (47). As depicted in Fig 16, the resin-bound tripeptides reacted with activated kojic acid 23. After cleavage, the kojic acid-tripeptide conjugates 26 were obtained in good yields. Most of the kojic acid-tripeptide conjugates exhibited more potent tyrosinase inhibitory activities than kojic acid. The most potent compound (kojic acidFWY) was about 100-fold more potent than kojic acid. Furthermore, it was less toxic than kojic acid and its storage<smiles>[R]C(NC(=O)OCc1cc(=O)c(O)co1)C(N)=O</smiles>

KA-AA-NH

(24)

Figure 14 Synthesis of kojic acid-amino acid amide conjugates (24, KA-AA- $\left.\mathrm{NH}_{2}\right)$<smiles>NC(=O)C(Cc1ccccc1)NC(=O)OCc1cc(=O)c(O)co1</smiles>

Figure 15 Structure of kojic acid-phenylalanine amide conjugate (24a) 


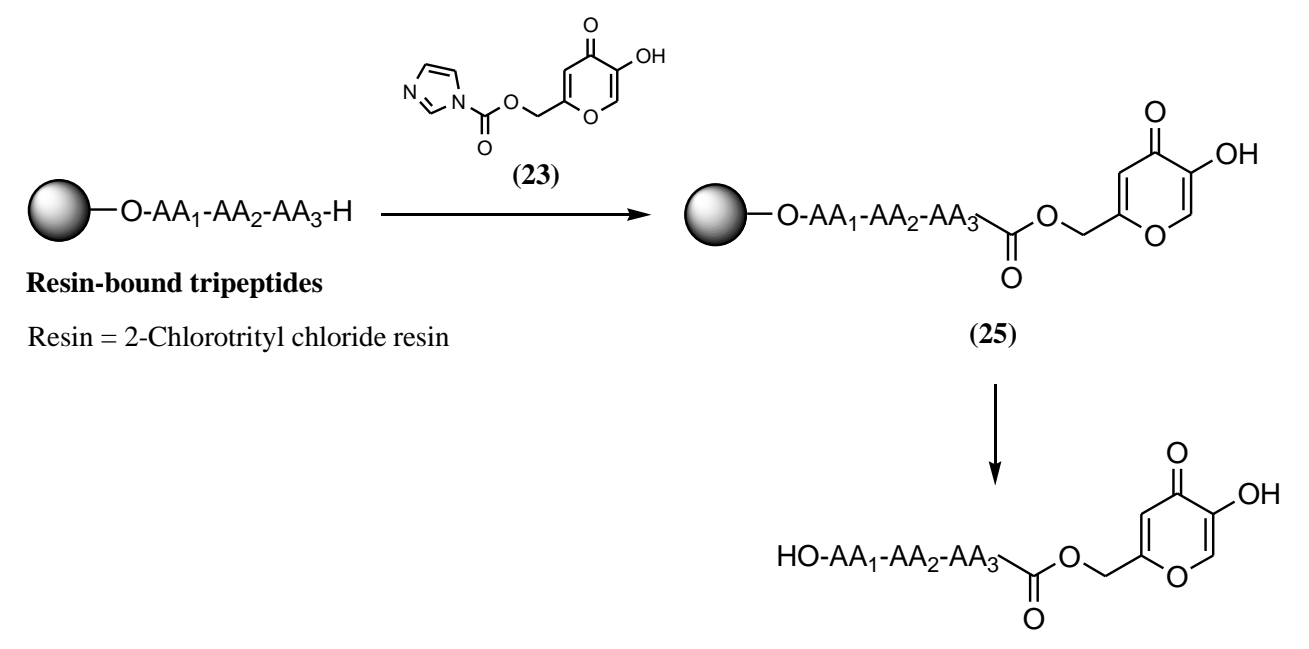

(26)

Figure 16 Solid-phase synthesis of kojic acid-tripeptides $\mathbf{2 6}$

stabilities was approximately 15-times higher than that of kojic acid. In addition, this research group demonstrated that kojic acid-tripeptide amides have similar tyrosinase inhibitory relative to kojic acidtripeptide free acids, while exhibit more favorable storage stability. These findings indicate the importance of C-terminal amide form in kojic acid-peptide conjugates.

Compounds containing two molecules of kojic acid

In a study by Kobayashi et al., various amino acid derivatives of kojic acid (28, Fig 17) were synthesized to improve the tyrosinase inhibitory activity of kojic acid (48). The $N$-kojic-amino acid 27 were synthesized starting from kojic acid and appropriate amino acid by using DSC $\left(N, N{ }^{\prime}-\right.$ disuccinimidylcarbonate) and DMAP (4dimethylaminopyridine). $\quad$ Subsequent esterification of another molecule of kojic acid with compound 27 gave the target compounds 28. Almost all synthesized compounds were more active than kojic acid. In general, $N$-kojicamino acid-kojiate $\mathbf{2 8}$ was found to have a higher inhibitory activity than $N$-kojic-amino acid 27. Among them, the $N$-kojic-Lphenylalanylkojiate was the most potent compound. It was 380 times more potent<smiles>O=c1cc(CO)occ1O</smiles>

(1)

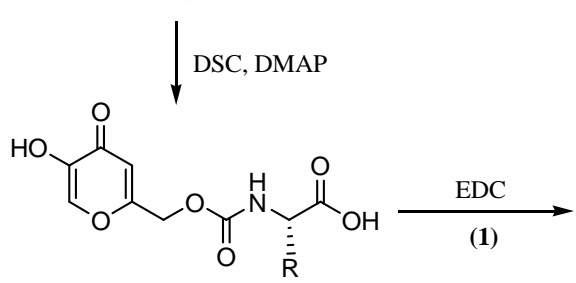

(27)<smiles>[R]C(NC(=O)OCc1cc(=O)c(O)co1)C(=O)OCc1cc(=O)c(O)co1</smiles>

(28)

Figure 17 Synthesis of $N$-kojic-amino acid-kojiate (28) 
than kojic acid. The inhibition mechanism of these derivatives is considered to be non-competitive which is similar to that of kojic acid (48). In another study, two molecules of kojic acid were connected by various linkers containing chemical bonds such as ester, amide and thioether (Fig. 18) (49). Chlorokojic acid (10) was reacted with sodium azide in DMF and subsequently converted to kojyl amine $\mathrm{HBr}$ 29. The coupling of compound 29 with succinyl chloride in the presence of triethylamine in THF afforded dikojylsuccinic amide 30. The nucleophilic substitution of chlorokojic acid (10) with potassium salt of kojyl succinic acid gave di-kojylsuccinate 31. The reaction of compound $\mathbf{1 0}$ with dithiols in the presence of TEA afforded thioethers 32 (Fig. 18).

The synthesized dimmers of kojic acid (30-32) were evaluated against tyrosinase enzyme and melanin formation in melan-a melanocytes. Among them, dithioether derivatives (32a-c) showed the highest inhibitory activity. The obtained results showed that the dithioether linker and its flexibility are important for improving anti- melanogenic activity. The propylene thioether compound $\mathbf{3 2 b}$ with $\mathrm{IC}_{50}$ value of $1.97 \mu \mathrm{M}$ was the most active inhibitor against tyrosinase enzyme. It was about 25fold more potent than kojic acid. In malan-a cell based assay, butylene dithioether derivative 32c exhibited superior inhibitory activity of melanin synthesis, being approximately 1000 times more potent than kojic acid (49). Moreover, compound 32b exhibited the most potent inhibitory activity of $\mathrm{NO}$ production in LPS activated macrophages (50).

Rho et al. further investigated the structureactivity relationship of kojic acid thioethers by preparing mono-kojyl thioethers 33, sulfoxides 34, and sulfones 35 (Fig. 19) (51). Kojyl thioethers 33 were prepared by the reaction of kojyl chloride $\mathbf{1 0}$ with potassium salts of thiols. Mono-oxidation of the thioethers $\mathbf{3 3}$ with MCPBA ( $m$-chloroperbenzoic acid) in $\mathrm{CH}_{2} \mathrm{Cl}_{2}$ produced sulfoxide derivatives 34 . The treatment of thioether derivatives 33 with oxone in a mixture of $\mathrm{MeOH} / \mathrm{H}_{2} \mathrm{O}$ afforded sulfone derivatives 35 . In the tyrosinase inhibition bioassay, the<smiles>NCc1cc(=O)c(O)co1</smiles>

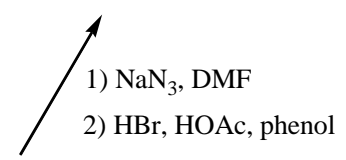<smiles>O=C(CCC(=O)OCc1cc(=O)c(O)co1)OCc1cc(=O)c(O)co1</smiles><smiles>O=C(O)CSCc1cc(=O)c(O)co1</smiles>

Figure 18 Synthesis of kojic acid dimmers 30-32 


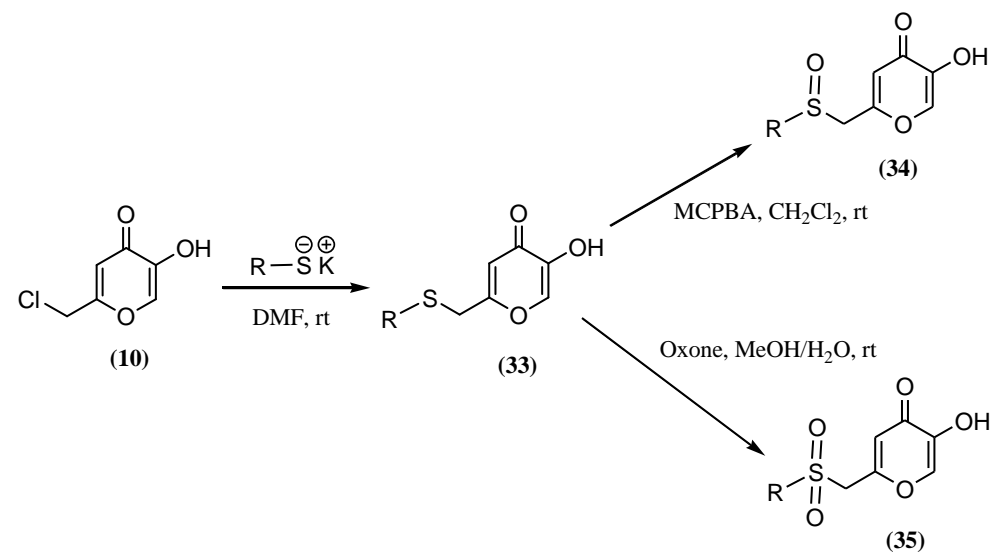

Figure 19 Synthesis of mono-kojyl thioethers 33, sulfoxides 34, and sulfones 35

pentyl, hexyl, and cyclohexyl thioethers exhibited potent inhibitory activity. In contrast, sulfoxide and sulfone derivatives $\mathbf{3 4}$ and $\mathbf{3 5}$ showed decreased activity. The pentyl thioether derivative with $\mathrm{IC}_{50}$ value of $0.097 \mu \mathrm{M}$ was the most potent compound against tyrosinase. The obtained results for inhibitory activity of NO production were similar to those of tyrosinase inhibition. Stilbene-like kojic acid derivative $\mathbf{4 2}$ was synthesized by joining two pyrone rings through an ethylene linkage by HornerEmmons reaction of the protected aldehyde 37 with phosphonate 40 (Fig. 20). Both<smiles>O=c1cc(CO)occ1O</smiles>

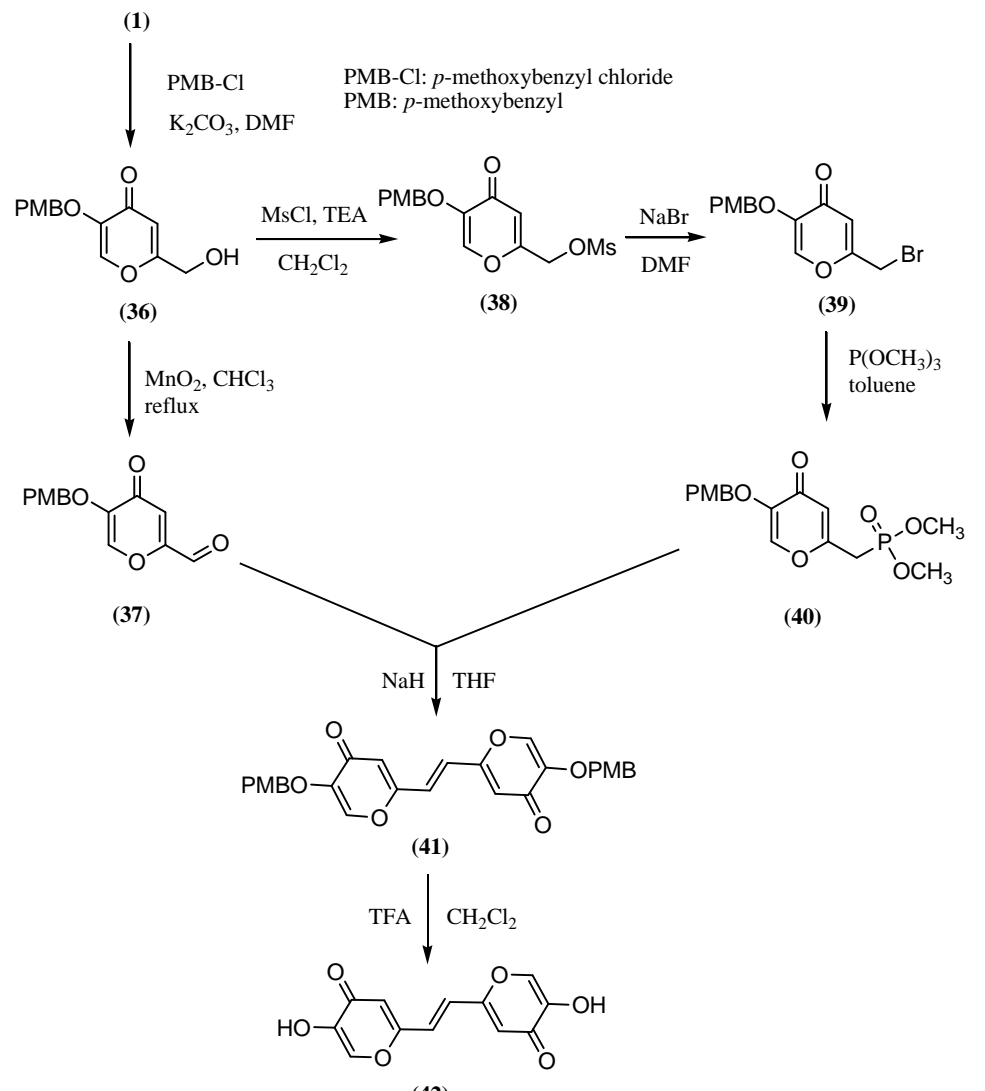

(42)

Figure 20 Synthesis of stilbene-like kojic acid derivative $\mathbf{4 2}$ 
intermediates $\mathbf{3 7}$ and $\mathbf{4 0}$ were derived from kojic acid as depicted in Fig. 20. The enzymatic assay revealed that the tyrosinase inhibitory activity of compound 42 was about 8 times more potent than that of kojic acid. This compound also exhibited significant melanin synthesis inhibitory activity in cell-based assay. The obtained results for dimeric compound $\mathbf{4 2}$ compared to kojic acid indicate that the connection of two pyrone rings of kojic acid through a suitable linker can be an useful strategy for finding new potent tyrosinase inhibitors (3).

C-2 Side chain-modified kojic acid derivatives

Chemically, the 2-(hydroxymethyl) side chain in the kojic acid structure is a good site for oxidation to related aldehyde. With a key intermediate aldehyde in hand, diverse derivatives can be prepared. As shown in Fig. 20, for oxidation of primary alcohol in kojic acid structure, the enolic $\mathrm{OH}$ should be protected with a suitable group such as p-methoxybenzyl. The oxidation of protected kojic acid 36 with $\mathrm{MnO}_{2}$ resulted in protected aldehyde 37. Kang et al. used this intermediate for synthesis of pyronyl-acrylic acid esters 44, which share structural features of kojic acid and hydroxylated cinnamic acid (caffeic acid, 43, Fig. 21) (52).
Horner-Emmons condensation of aldehyde 37 with compound $\mathbf{4 5}$ gave methyl ester 46, which hydrolyzed with $\mathrm{LiOH}$ in aqueous THF to afford acid 47. Compound 47 was $O$-alkylated with appropriate alkyl iodides or alkyl tosylates. The target compounds 44 were obtained by removing of the PMB-protecting group using trifluoroacetic acid (TFA) in $\mathrm{CH}_{2} \mathrm{Cl}_{2}$ (Fig. 22).

The abilities of synthesized compound $\mathbf{4 4}$ to inhibit tyrosinase and melanin production were evaluated by Kang et al. Among the tested derivatives, compounds derived from diethylene glycol were found to inhibit melanin production at $20 \mu \mathrm{g} / \mathrm{ml}$. It should be noted that in this test, kojic acid inhibited melanin production at 200 $\mu \mathrm{g} / \mathrm{ml}$ (52).

Yi et al. have synthesized thiosemicarbazone analogs of kojic acid (52) as tyrosinase inhibitors (53). The synthesis of the target compounds 52a,b was outlined in Fig. 23. Firstly $O$-methyl kojic acid (49) was oxidized to aldehyde $\mathbf{5 0}$ by using $\mathrm{MnO}_{2}$. The $O$-methyl group was removed by $\mathrm{AlCl}_{3}$ to give compound 51. The condensation reaction of carboxaldehydes $\mathbf{5 0}$ or $\mathbf{5 1}$ with the thiosemicarbazide in anhydrous ethanol in the presence of acetic acid afforded corresponding thiosemicarbazone analogs 52. The inhibitory evaluation of

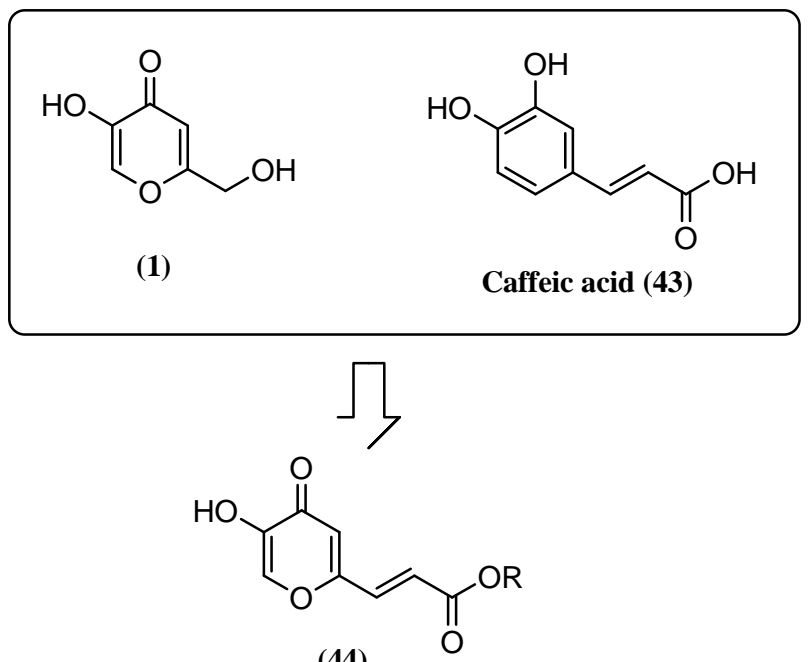

(44)

Figure 21 Design of hybrid compounds pyronyl-acrylic acid esters 44 


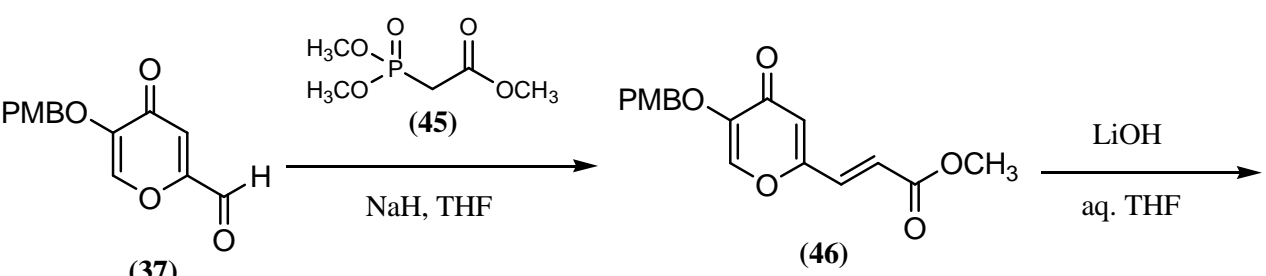

(46)<smiles>[R16]OC(=O)/C=C/c1cc(=O)c(O)co1</smiles>

(47)

(48)

(44)

Figure 22 Synthesis of hybrid compounds pyronyl-acrylic acid esters 44

compounds 52a,b against commercial mushroom tyrosinase revealed that $O$ methylated compound 52a showed no inhibitory activity, while thiosemicarbazone analog $\mathbf{5 2 b}$ bearing a free enolic group exhibited high activity against mushroom tyrosinase $\left(\mathrm{IC}_{50}=11\right.$ $\mu \mathrm{M})$. The latter compound was about 9fold more potent than the parent compound kojic acid (53).

\section{Miscellaneous derivatives}

The topical formulations of kojic acid are used as skin-lightening agent. However, it is hardly absorbed through the lipid membrane of its target sites, the melanocytes due to its hydrophilic character (54). In some investigations, it has been attempted to connect the kojic acid to a suitable carrier.

Kim et al. synthesized a kojic acid analog<smiles>COc1coc(CO)cc1=O</smiles>

(49)

(50)

(51)<smiles>CCOC(=O)CCCCOC(N)=S</smiles>

(52a)<smiles></smiles>

(52b)

Figure 23 Synthetic pathway to thiosemicarbazone analogs of kojic acid (52) 
(kojyl-APPA, 56) containing 5-[(3aminopropyl)phosphinooxy]- moiety as stable derivative of kojic acid. Compound 56 was prepared by the reaction of kojic acid with 2-chloro-[1,3,2] oxazaphosphinane 2-oxide (54) in the presence of TEA in $\mathrm{CHCl}_{3} / \mathrm{EtOH}$, followed by hydrolysis in acidic medium of $\mathrm{H}_{2} \mathrm{O} / \mathrm{MeOH}$ (Fig. 24). Interestingly, the alcoholic $\mathrm{OH}$ group of kojic acid did not take part in reaction with compound $\mathbf{5 4}$. The effects of compound $\mathbf{5 6}$ on tyrosinase activity and melanin synthesis were evaluated by Kim and co-workers. The masked form of kojic acid $\mathbf{5 6}$ displayed higher stability than kojic acid. Also, its permeation through the skin was about 8times more than kojic acid. Compound 54 showed no tyrosinase inhibition effect compared with kojic acid in vitro, however displayed the same inhibitory effect as kojic acid on melanin synthesis in mouse melanoma and normal human melanocytes.
It seems that compound $\mathbf{5 6}$ is converted to kojic acid in living cells (55). In another study, Manosroi and co-workers have investigated the entrapment of kojic acid and its oleate ester. Kojic oleate (57) was prepared starting from kojic acid and oleic acid in $\mathrm{CH}_{2} \mathrm{Cl}_{2}$ by using DCC $(N, N$ 'dicyclohexylcarbodiimide) and DMAP (4( $N, N$-dimethylamino)pyridine) (Fig. 25). In this study, the entrapment efficiencies of kojic acid and kojic oleate in the vesicles were investigated by dialysis and column chromatography, respectively. The obtained results indicated that kojic oleate could be intercalated in the bilayer structure of the vesicles composed of amphiphile (Span 60, Tween 61 or DPPC)/cholesterol/dicetyl phosphate at molar ratio of 9.5:9.5:1.0. In general, they concluded that the esterification of kojic acid improved its entrapment in the vesicles (56).

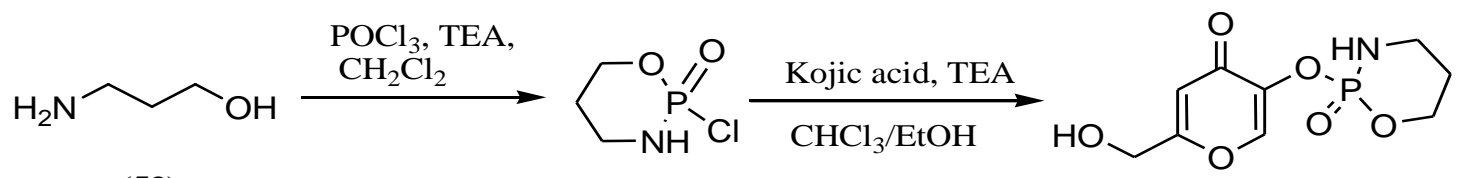
(53)<smiles>[NH3+]CCCOP(=O)([O-])Oc1coc(CO)cc1=O</smiles>

(56)<smiles>CCCCCCCC/C=C\CCCCCCCC(=O)OCc1cc(=O)c(O)co1</smiles> 


\section{Conclusion}

Kojic acid is a small-molecule with tyrosinase inhibitory activity, which has been used a skin-lightening agent. This agent is the most intensively studied inhibitor of tyrosinase; however it has unsatisfactory inhibitory activity, insufficient stability band unwanted side effects. To overcome these disadvantages, researchers have attempted to design new analogs of kojic acid with higher potency, satisfactory stability and safety. Diverse modifications on this small-molecule have

\section{References}

1. Parvez Sh, Kang M, Chung HS, Cho C, Hong MC, Shin MK, Bae H. Survey and mechanism of skin depigmenting and lightening agents. Phytother Res 2006;20:921-34.

2. Shi YL, Benzie IFF, Buswell JA. Role of tyrosinase in the genoprotective effect of the edible mushroom Agaricus bisporus. Life Sci 2002;70:1595-1608.

3. Lee YS, Park JH, Kim MH, Seo SH, Kim HJ. Synthesis of tyrosinase inhibitory kojic acid derivative. Arch Pharm Chem Life Sci 2006;339:111-4.

4. Yan Q, Cao R, Yi W, Chen Z, Wen H, Ma L, Song H. Inhibitory effects of 5benzylidene barbiturate derivatives on mushroom tyrosinase and their antibacterial activities. Eur J Med Chem 2009;44:423543.

5. Sánchez-Ferrer A, Rodríguez-López JN, García-Cánovas F, García-Garmona F. Tyrosinase: a comprehensive review of its mechanism. Biochim Biophys Acta 1995;1247:1-11.

6. Seo SY, Sharma VK, Sharma N. Mushroom tyrosinase: recent prospects. J Agric Food Chem 2003;51:2837-53.

7. Masuda T, Yamashita D, Takeda Y, Yonemori S. Screening for tyrosinase inhibitors among extracts of seashore plants and identification of potent inhibitors from Garcinia subelliptica. Biosci Biotechnol Biochem 2005;69:197-201.

8. Solano F, Briganti S, Picardo M, Ghanem G. Hypopigmenting agents: an updated review on biological, chemical and clinical aspects. Pigment Cell Res 2006;19:550-71.

9. Kim YJ, Uyama H. Tyrosinase inhibitors from natural and synthetic sources: structure, inhibition mechanism and perspective for the future. Cell Mol Life Sci 2005;62:1707-23.

10. Nihei K, Yamagiwa $Y$, Kamikawa $T$, Kubo I. 2-Hydroxy-4-isopropylbenzaldehyde, a potent partial tyrosinase inhibitor. Bioorg Med Chem Lett 2004;14:681-83.

11. Yi W, Cao R, Peng W, Wen $H$, Yan Q, Zhou B, Ma L, Song H. Synthesis and been made to find new tyrosinase inhibitors. The main modifications were conversion of the $\gamma$-pyranone to 4pyridinone, esterification of 2(hydroxymethyl) group, C-2 side chainmodification, and conjugation of kojic acid with amino acids.

\section{Conflict of interest statement}

The authors claim that they have no conflicting interest in this study. biological evaluation of novel 4hydroxybenzaldehyde derivatives as tyrosinase inhibitors. Eur J Med Chem 2010;45:639-46.

12. Lam KW, Syahida A, UI-Haq Z, Rahman MBA, Lajis NH. Synthesis and biological activity of oxadiazole and triazolothiadiazole derivatives as tyrosinase inhibitors. Bioorg Med Chem Lett 2010;20:3755-9.

13. Burdock GA, Soni MG, Carabin IG. Evaluation of health aspects of kojic acid in food. Regulatory Toxicol Pharmacol 2001;33:80-101.

14. Moon KY, Ahn KS, Lee J, Kim YS. Kojic acid, a potential inhibitor of NF-kappa B activation in transfectant human $\mathrm{HaCaT}$ and SCC-13 cells. Arch Pharm Res 2001;24:307-11.

15. Piamphongsant $T$. Treatment of melasma: a review with personal experience. Int $\mathrm{J}$ Dermatol 1998;37:897-903.

16. Cabanes J, Chazarra S, Garcia-Carmona F. Kojic acid, a cosmetic skin whitening agent, is a slow-binding inhibitor of catecholase activity of tyrosinase. J Pharm Pharmacol 1994;46:982-5.

17. Hryniewicz K, Stadnicka K, Pattek-Janczyk A. Crystal structure and vibrational spectra of 2-chloromethyl-5-hydroxy-4H-pyran-4one as potential ligands for $\mathrm{Fe}(\mathrm{III})$ complexes. J Mol Struct 2009;919:255-70.

18. Zaremba K, Lasocha W, Adamski A, Stanek J, Pattek-Janczyk A. Crystal structure and magnetic properties of tris(2-hydroxymethyl-4-oxo- $4 H$ pyran-5-olato $\mathrm{\kappa} 2 \mathrm{O} 5$, O4)iron(III). J Coord Chem 2007;60:1537-46.

19. Yang CT, Sreerama SG, Hsieh WY, Liu S. Synthesis and characterisation of a novel macrocyclic chelator with 3-hydroxy-4pyrone chelating arms and its complexes with medicinally important metals. Inorg Chem 2008;47:2719-27.

20. Emami S, Hosseinimehr SJ, Taghdisi SM, Akhlaghpoor S. Kojic acid and its manganase and zinc complexes as potential radioprotective agents. Bioorg Med Chem Lett 2007;17:45-8. 
21. Moggia F, Brisset $H$, Fages F, Chaix C, Mandrand B, Dias M, Levillain E. Design, synthesis and redox properties of two ferrocene-containing iron chelators. Tetrahedron Lett 2006;47:3371-74.

22. Stenson AC, Cioffi EA. Speciation of M+3hydroxypyrone chelation complexes by electrospray ionization ion trap and Fourier transform ion cyclotron resonance mass spectrometry. Rapid Commun Mass Spectrom 2007;21:2594-2600.

23. Brtko J, Rondahl L, Fickova M, Hudecova D, Eybl V, Uher M. Kojic acid and its derivatives: history and present state of art. Cent Eur J Publ Health 2004;12:16-18.

24. Sudhir PR, Wu HF, Zhou ZC. Probing the interaction of kojic acid antibiotics with iron(III) chloride by using electrospray tandem mass spectrometry. Rapid Commun Mass Spectrom 2005;19:209-12.

25. Zborowski $\mathrm{K}$, Grybos $\mathrm{R}$, Proniewicz L $\mathrm{M}$. Molecular structure of oxovanadium (IV) complexes with maltol and kojic acid: a quantum mechanical study. Inorg Chem Commun 2005;8:76-8.

26. Emami S, Ghafouri E, Faramarzi MA, Samadi N, Irannejad $\mathrm{H}$, Foroumadi A. Mannich bases of 7-piperazinylquinolones and kojic acid derivatives: synthesis, in vitro antibacterial activity and in silico study. Eur J Med Chem 2013;68:185-191.

27. Aytemir MD, Hider RC, Erol DD, Özalp M, Ekizoğlu M. Synthesis of new antimicrobial agents; amide derivatives of pyranones and pyridinones. Turk J Chem 2003;4:445-52.

28. Melník M, Uher M, Brtko J, Mrozińska D, Mroziński J. Cooper(II) kojates and their antifungal effects. Polish J Chem 1993;67:1219-25

29. Hudecová D, Uher M, Brtko J. Halogen derivatives of kojic acid with antifungal effects. Biologia 1992;47:483-8.

30. Aytemir MD, Özçelik B. A study of cytotoxicity of novel chlorokojic acid derivatives with their antimicrobial and antiviral activities. Eur J Med Chem 2010;45:4089-95.

31. Kojic acid as an anti-inflammatory and analgesic agent. Japan Kokai Tokkyo Koho JP 80154916, 1980.

32. Bransová J, Brtko J, Uher M, Novotný L. Antileukemic activity of 4-pyranone derivatives. Int $\mathrm{J}$ Biochem Cell Biol 1995;27:701-6.

33. Bransová J, Uher M, Brtko J. Regulation of selected biological processes in neoplastic cell lines by halogen derivatives of 5-hydroxy-2hydroxymethyl-4-pyranone. Anticancer Res 1998;18:4423-8.

34. Fickova M, Pravdova E, Rondhai L, Uher M, Brtko J. In vitro antiproliferative and cytotoxic activities of novel kojic acid derivatives: 5benzyloxy-2-selenocyanotomethyl- and 5methoxy-2- selenocyanotomethyl-4-pyranone. J App Toxicol 2008;28:554-9.

35. Uher $M$, Konečnỳ $\mathrm{V}$, Rajniaková $\mathrm{O}$. Synthesis of 5-hydoxy-2-hydroxymethyl4H-pyran-4-one derivatives with pesticide activity. Chem Papers 1994;48:282-4.
36. Xiong X, Pirrung MC. Modular synthesis of candidate indole-based insulin mimics by Claisen rearrangement. Org Lett 2008;10:1151-4.

37. Aytemir MD, Septioğlu E, Çalış Ü. Synthesis and anticonvulsant activity of new kojic acid derivatives. Arzneim Forsch Drug Res 2010;60:22-9.

38. Aytemir MD, Çalış Ü. Anticonvulsant and neurotoxicity evaluation of some novel kojic acids and allomaltol derivatives. Arch Pharm Med Chem Life Sci 2010;343:17381.

39. Li DF, Hu P P, Liu M S, Kong X L, Zhang J $\mathrm{C}$, Hider $\mathrm{R} \mathrm{C}$, et al. Design and synthesis of hydroxypyridinone-L-phenylalanine conjugates as potential tyrosinase inhibitors. J Agric Food Chem 2013;61:6597-03.

40. Saghaie L, Pourfarzam M, Fassihi A, Sartippour B. Synthesis and tyrosinase inhibitory properties of some novel kojic acid. Res Pharm Sci 2013;8:233-42.

41. Brown GC, Bal-Price A. Inflammatory neurodegeneration mediated by nitric oxide, glutamate, and mitochondria. Mol Neurobiol 2003;27:325-55.

42. Rho HS, Goh M, Lee J, Ahn SM, Yeon J, Yoo DS, , et al. Ester derivatives of kojic acid and polyphenols containing adamantane moiety with tyrosinase inhibitory and anti-inflammatory properties. Bull Korean Chem Soc 2011;32:1411-4.

43. Cho JC, Rho HS, Joo YH, Lee CS, Lee J, Ahn SM, et al. Depigmenting activities of kojic acid derivatives without tyrosinase inhibitory activities. Bioorg Med Chem Lett 2012;22:4159-62.

44. Cho JC, Rho HS, Baek HS, Ahn SM, Woob BY, Hong YD, et al. Depigmenting activity of new kojic acid derivative obtained as a side product in the synthesis of cinnamate of kojic acid. Bioorg Med Chem Lett 2012;22:2004-7.

45. Ahn SM, Rho HS, Baek HS, Joo YH, Hong YD, Shin SS, et al. Inhibitory activity of novel kojic acid derivative containing trolox moiety on melanogenesis. Bioorg Med Chem Lett 2011;21:7466-9.

46. Noh JM, Kwak SY, Seo HS, Seo JH, Kim B-G, LeeYS. Kojic acid-amino acid conjugates as tyrosinase inhibitors. Bioorg Med Chem Lett 2009; 19:5586-9.

47. Kim H, Choi J, Cho JK, Kim SY, Lee YS. Solid-phase synthesis of kojic acidtripeptides and their tyrosinase inhibitory activity, storage stability, and toxicity. Bioorg Med Chem Lett 2004;14:2843-6.

48. Kobayashi $\mathrm{Y}$, Kayahara H, Tadasa K, Tanaka H. Synthesis of $N$-kojic-amino acid and $N$-kojic-amino acid-kojiate and their tyrosinase inhibitory activity. Bioorg Med Chem Lett 1996;6:1303-8.

49. Rho HS, Baek HS, Ahn SM, Kim DH, Chang IS. Synthesis of new antimelanogenic compounds containing two molecules of koji acid. Bull Korean Chem Soc 2008;29:1569-71.

50. Yoo DS, Lee J, Choi SS, Rho HS, Cho DH, Shin WC, Cho JY. A modulatory effect of 


\section{Hashemi et al.}

novel kojic acid derivatives on cancer cell proliferation and macrophage activation. Pharmazie 2010;65:261-6.

51. Rho HS, Ahn SM, Yoo DS, Kim MK, Cho DH, Cho JY. Kojylthioether derivatives having both tyrosinase inhibitory and antiinflammatory properties. Bioorg Med Chem Lett 2010;20:6569-71.

52. Kang SS, Kim HJ, Jin C, Lee YS. Synthesis of tyrosinase inhibitory (4-oxo-4H-pyran-2yl)acrylic acid ester derivatives. Bioorg Med Chem Lett 2009; 19:188-91.

53. Yi W, Dubois $\mathrm{C}$, Yahiaoui $\mathrm{S}$, Haudecoeur $\mathrm{R}$, Belle C, Song $\mathrm{H}$, et al. Refinement of arylthiosemicarbazone pharmacophore in inhibition of mushroom tyrosinase. Eur $\mathrm{J}$ Med Chem 2011;46:4330-5.
54. Curto EV, Kwong C, Hermerdorfer H, Glatt $\mathrm{H}$, Santis C, Virador V, et al. Inhibitors of mammalian melanocyte tyrosinase: in vitro comparisons of alkyl esters of gentisic acid with other putative inhibitors. Biochem Pharmacol 1991;57:663-2.

55. Kim DH, Hwang JS, Baek HS, Kim KJ, Lee BG, Chang I, et al. Development of 5-[(3aminopropyl)phosphinooxy]-2-(hydroxymethyl)$4 \mathrm{H}$-pyran-4-one as a novel whitening agent. Chem Pharm Bull 2003;51:113-6.

56. Manosroi A, Wongtrakul $\mathrm{P}$, Manosroi J, Midorikawa U, Hanyu Y, Yuasa M, et al. The entrapment of kojic oleate in bilayer vesicles. Int J Pharm 2005;298:13-25. 